\title{
3D CFD Simulation and Experimental Validation of Small APC Slow Flyer Propeller Blade
}

\author{
Hairuniza Ahmed Kutty ${ }^{\dagger}$ and Parvathy Rajendran ${ }^{\dagger, *}$ \\ School of Aerospace Engineering, Universiti Sains Malaysia, Penang 14300, Malaysia; \\ hairunizaahmed@gmail.com \\ * Correspondence: aeparvathy@usm.my; Tel.: +60-4-599-5963 \\ + These authors contributed equally to this work. \\ Academic Editor: Erinc Erdem \\ Received: 16 January 2017; Accepted: 22 February 2017; Published: 25 February 2017
}

\begin{abstract}
The current work presents the numerical prediction method to determine small-scale propeller performance. The study is implemented using the commercially available computational fluid dynamics (CFD) solver, FLUENT. Numerical results are compared with the available experimental data for an advanced precision composites (APC) Slow Flyer propeller blade to determine the discrepancy of the thrust coefficient, power coefficient, and efficiencies. The study utilized unstructured tetrahedron meshing throughout the analysis, with a standard k- $\omega$ turbulence model. The Multiple Reference Frame model was also used to consider the rotation of the propeller toward its local reference frame at 3008 revolutions per minute (RPM). Results show reliable thrust coefficient, power coefficient, and efficiency data for the case of low advance ratio and an advance ratio less than the negative thrust conditions.
\end{abstract}

Keywords: APC slow flyer; CFD; k-w; multiple reference frame; propeller; blade; unmanned aerial vehicle (UAV) propeller

\section{Introduction}

A propeller may be considered as a rotating wing that assembles airfoils collectively, comparable to the cross-section of the wing of an aircraft. A basic propeller configuration includes a minimum of two blades, attached together to the central hub [1]. Thrust is generated to push the aircraft forward through the air, by converting the rotation power from the engine shaft. The chamber shape of the airfoil causes the airflow in front of the blade to travel at higher speed.

Based on Bernoulli's principle, due to the acceleration of the airflow, it causes a reduction of static pressure in front of the blade. Meanwhile, lower speed at the back of the propeller causes the propeller to experience higher static pressure. Thus, as the pressure is lower at the front, the aircraft is pulled forward due to the reaction force. The pressure difference between the front and back section of the propeller creates thrust force in forward directions, allowing it to overcome the drag experienced by the aircraft [2].

Different methods are available to determine propeller performance, including experimental and numerical analysis. In the experimental method, the propeller blade is tested in a wind tunnel for both static and advancing flow conditions. Meanwhile, numerical analysis adopts three-dimensional computational fluid dynamics (CFD) simulation, utilizing the Reynolds-average Navier-Stokes (RANS) equation. CFD methods have become significant and highly useful tools for propeller design and analysis.

Whereas the performance of the propeller for full-scale conventional aircraft has been well-documented using either of the stated methods, little research has been conducted in the case of low Reynolds numbers and small-scale propellers [3]. Generally, the propellers used for the 
Unmanned Aerial Vehicles (UAVs) have a small diameter, operate at low Reynolds number and low tip speed [4]. Reynolds number considered in this study is less than 100,000 based on the chord at $75 \%$ span location [3,5]. The development and usage of UAVs have increased significantly over the last decades [4]. Thus, it is very important to investigate the propeller performance to ensure that the design has led to a reliable UAV performance.

Since the usage of aircraft propellers was pioneered, numerous designs have evolved to cope with the rapid progress of aerospace technologies. Various propeller designs are available, serving aircraft with different mission profiles. The quest for a highly efficient propeller performance is the aim of propeller improvements in airfoil selections, propeller diameters, blade angle, blade twist, and the number of blades. Most modification parameters revolve around the conventional design of a propeller blade, which includes a large-scale propeller used in conventional sized aircraft.

In the unconventional design of propeller blades, the size is smaller than 24 inches, operating at lower Reynolds number, low forward speed and high revolution per minute (RPM) [4]. The reliability of the unconventional design remains scarce because of limited studies and lack of documented propeller performance study methods.

The current study aims to provide an extensive investigation of one method to determine the performance of a propeller blade operating at a low Reynolds number. The current study seeks to perform flow simulations of a propeller blade using CFD software (FLUENT) to determine the thrust coefficient, power coefficient, and efficiency with a variation of the advance ratio. This paper intends to propose a validated method and setup capable of estimating propeller performance using CFD Fluent, thus further research need not perform a CFD setup study and validation prior to a new propeller design analysis.

There are several common methods available to determine propeller performance, which include experimental analysis and CFD. Brandt et al. [5] performed an experimental study utilizing a wind tunnel to determine the performance of 79 small-scale low Reynolds number propeller blades. The experiments were conducted at various wind tunnel speeds and ranges of rotational speed from 1500 to 7500 RPM.

The study shows that propeller performance degrades with reduction of rotational speed. Deters et al. [3] implemented the same method with a different type of propeller blade. The performance of 27 small-scale propellers was tested, and the data for thrust, power, and propeller efficiency for a certain range of advance ratio were collected. The experiments were intended to understand the Reynolds number effects on a small-scale propeller, as the aerodynamic performance such as lift and drag have a more pronounced effect at Reynolds number less than 100,000.

Results show that propeller performance improved as the Reynolds number increases. Merchant [6] also conducted an experimental method study to determine the performance for a propeller blade operating at a Reynolds number of 30,000 to 300,000. The experimental method used in the study manages to provide reliable sets of data for low Reynolds number applications.

Some studies used CFD because it is one of the most powerful tools to determine flow properties. Subhas et al. [7] performed a study on the ship propeller flow by implementing CFD analysis. The geometry was initially drawn in CAD software, with specific propeller dimensions and blade angles. A cylinder enclosure was taken as the flow domain, with the inlet at a distance of 3D (with D as the diameter of the propeller blade) from the blade, and the exit at 4D downstream of the same point.

The meshing was generated for the entire flow domain and propeller. The study uses the k- $\varepsilon$ turbulence model by incorporating a moving reference frame. Thrust and torque coefficient data obtained from CFD are compared with experimental results, with good matching between the two. The study concludes that CFD analysis may predict the flow characteristics with reasonable accuracy.

In addition, Wang et al. [8] analysed marine propeller performance using transition sensitive turbulence modelling for CFD analysis. The analysis provides the method to minimize the discrepancy between CFD and experimental results by including transitional analysis. The study proved that the 
results improved the prediction accuracy for propellers compared with the standard k- $\omega$ SST (Shear Stress Transport) turbulence model.

Morgut et al. [9] studied the influence of grid type and selection of turbulence model for numerical predictions of a marine propeller. Meshing of hexa-structured and hybrid unstructured meshes were compared, to study the impact of the meshes. Apart from that, the accuracy of SST and BSL-RSM (Baseline Reynolds Stress Model) were studied. The analysis exhibited a similar accuracy level for both meshes and BSL-RSM provides slightly better accuracy than SST with higher computational time.

Benini [10] performed a study to compare the procedures available to determine the performance of the propeller blade, including combined momentum-blade element theory and fully three-dimensional numerical RANS using CFD Fluent. The result shows that the numerical method used give reliable results independent of the advance ratio, with a maximum discrepancy of $5 \%$ compared to experimental results. In addition, the numerical analysis gives better results compared to the combined momentum-blade element theory.

Morgado et al. [11,12] developed a new propeller and analysis tool that can estimate the performance of a propeller. The software uses an improved blade element momentum for every blade section. The results were validated against experimental data referenced in the National Advisory Committee for Aeronautics (NACA) Technical Report. The capabilities of the software are further tested to design and optimize a new propeller [13].

\section{Methodology}

Generally, the propeller used in UAVs is less than 24 inches in diameter. Thus, in the current study, the advanced precision composites (APC) Slow Flyer propeller is set as the standard design as it is one of the common blades used for UAVs, and due to the availability in experimental data [14]. More details on the APC Slow Flyer are found in Section 3. The numerical simulation for this propeller is performed using the commercially available CFD solver FLUENT 15.0 released by ANSYS Inc., Canonsburg, PA, USA. CFD simulation was conducted over a range of propeller advance ratios, as summarized in Table 1 . The results obtained from the numerical analysis are compared with experimental data $[3,14]$ to validate the CFD method used to extract the propeller performance characteristics.

Table 1. Simulation flow conditions.

\begin{tabular}{cc}
\hline Advance Coefficient, $\boldsymbol{J}$ & Free Stream Velocity $(\mathrm{m} / \mathbf{s})$ \\
\hline 0.192 & 2.4384 \\
0.236 & 2.9972 \\
0.282 & 3.5814 \\
0.334 & 4.2418 \\
0.383 & 4.8641 \\
0.432 & 5.4864 \\
0.486 & 6.1722 \\
0.527 & 6.6929 \\
0.573 & 7.2771 \\
0.628 & 7.9756 \\
0.659 & 8.3693 \\
0.717 & 9.1059 \\
0.773 & 9.8171 \\
0.799 & 10.1473 \\
\hline
\end{tabular}

\section{Propeller Model}

The APC Slow Flyer is a two-bladed propeller, with a fixed pitch and a diameter of $0.254 \mathrm{~m}$. The propeller consists of thin airfoil profiles with a specific combination of a low Reynolds number Eppler E63 and a Clark-Y airfoil near the tip [15], inserted to form a sharp leading edge blade design, as shown in Figure 1. 


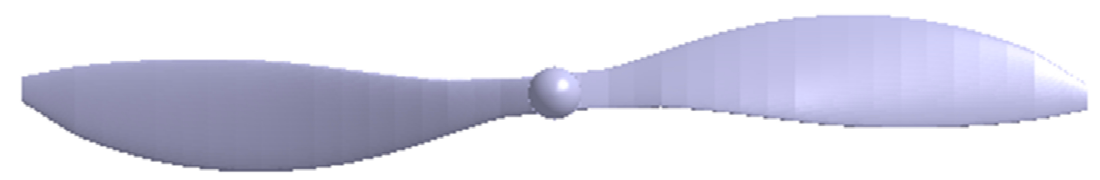

Figure 1. Standard APC Slow Flyer 10 inches $\times 7$ inches propeller blade.

The pitch of $0.1778 \mathrm{~m}$ provides a pitch-to-diameter ratio of 0.7 , which is common for an off-shelf propeller type. The Reynolds number of the propeller is approximately 50,804, which is defined by the rotational speed of 3008 RPM and a chord at a 75\% blade station. The APC Slow Flyer used in this study, as shown in Figure 1, is modelled using CAD software prior to analysis in FLUENT 15.0.

\section{Numerical Setup}

The setup used in the numerical analysis is further explained in this section.

\subsection{Flow Domain}

The numerical predictions presented in this study were performed using the ANSYS FLUENT 15.0 commercial CFD solver. The Multiple Reference Frame model (MRF) approach was used to numerically predict the flow around the propeller. The domain is defined and illustrated in Figure 2a. The domain is split into a global stationary domain and a subdivided rotating region, called the rotating domain. The rotating domain is specified by a smaller cylinder entirely enclosing the blades and the hub as shown in Figure $2 b$.

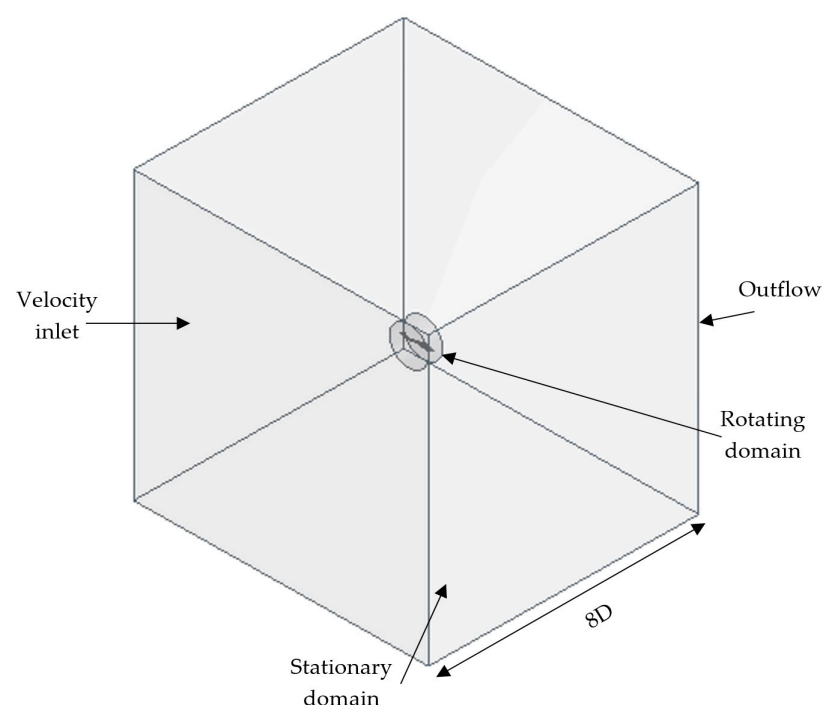

(a)

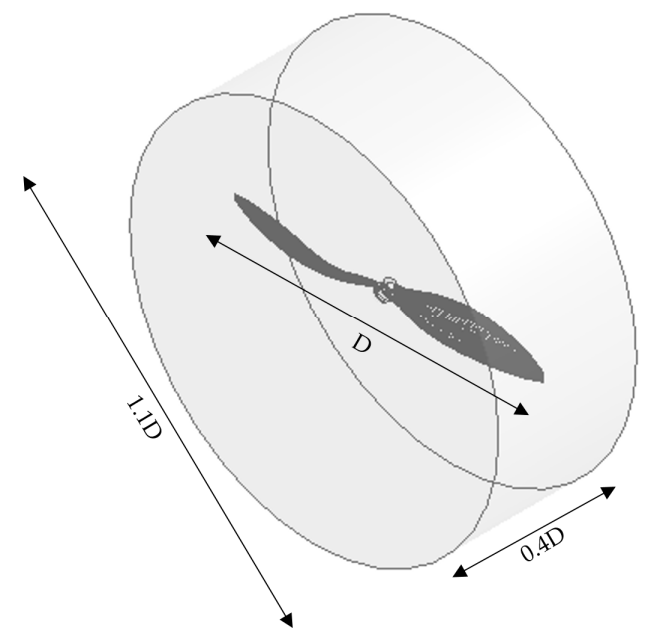

(b)

Figure 2. Flow domain and boundary conditions. (a) Stationary domain and boundary conditions. The boundary conditions include an inlet, outlet, stationary domain, and rotating domain; (b) Rotating domain.

The inlet, outlet, and outer boundaries of the stationary region are placed far enough from the propeller to prevent the full development of the upstream and downstream flow from affecting the results of the analysis. The inlet and outlet boundaries are located $4 \mathrm{D}$, both upstream and downstream of the origin of the propeller. For the rotating domain, the enclosure is set to be 1.1D and 0.4D. Proper selection of the flow domain upstream and downstream distance is very important to prevent recirculation of the flow that will cause convergence problems [16]. 


\subsection{Mesh Generation}

The grid was generated using a mesh tool in FLUENT 15.0. The grid is important because it provides the individual representation of the geometry of interest. The quality of the computational grid directly influenced the rate of convergence, the performance obtained from the numerical analysis, and computational time to run the analysis. For the current study, the cell sizes of the mesh were generated to be in a smaller range along the blade in the rotating region and to gradually increase toward the stationary region. Ensuring sufficient grid refinements across the interface enhances the accuracy of the results.

The grid is fully tetrahedral unstructured in both stationary and rotating domains. The selection is based on the justifications that unstructured tetrahedral grids have the capabilities to discretize complex geometries with fast and minimum user intervention. Table 2 shows the details for mesh grid generation. Adaptation of the grid to the physical solution-that is grid refinement or coarsening-is easier to accomplish on an unstructured than on a structured grid.

Table 2. Details of the meshing grid.

\begin{tabular}{cc}
\hline Use Advance Size Function & Curvature \\
\hline Relevance Centre & Fine \\
Curvature Normal Angle & $40^{\circ}$ \\
Min Size & $1 \times 10^{-4} \mathrm{~m}$ \\
Max Face Size & $5.6718 \times 10^{-2} \mathrm{~m}$ \\
Max Size & $0.113440 \mathrm{~m}$ \\
Growth Rate & 1.20 \\
Minimum Edge Length & $3.9199 \times 10^{-6} \mathrm{~m}$ \\
\hline
\end{tabular}

Figure 3 below shows the surface mesh of the propeller blade where Figure 3a shows the standard mesh, Figure $3 b$ the coarse mesh, Figure $3 c$ mid mesh, Figure $3 d$ the mid-fine mesh and finally Figure 3e the fine mesh. Table 3 shows the numbers of cells, nodes and faces for the respective meshes. The cells sizes near the blade wall are smaller and increase towards the outer boundary.

(a)

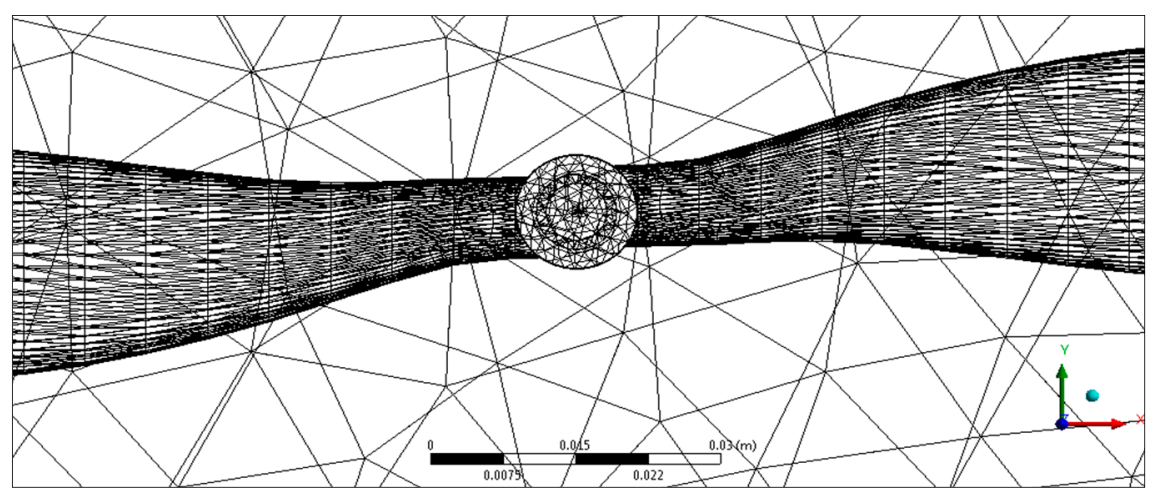

Figure 3. Cont. 
(b)

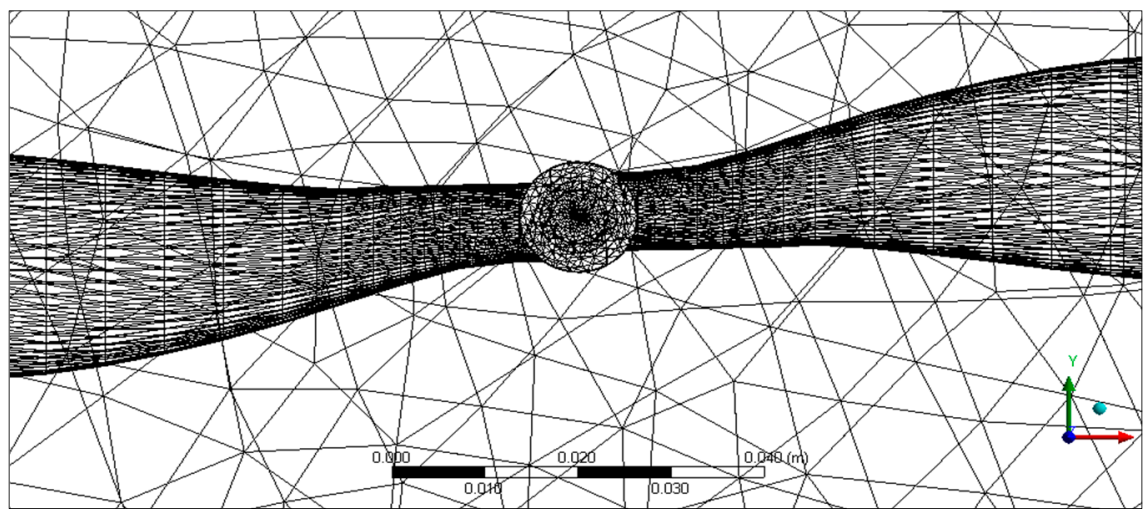

(c)



(d)

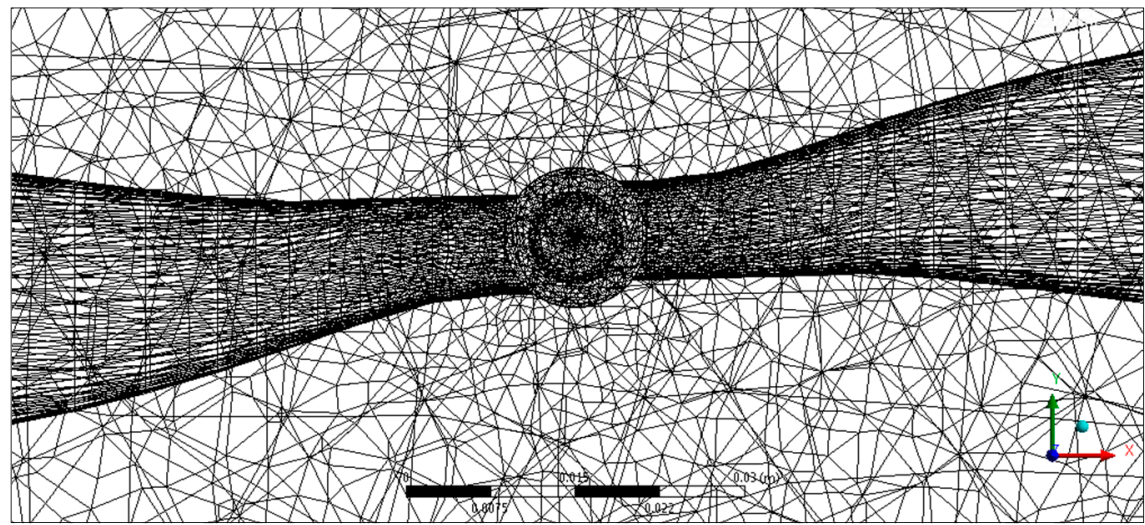

(e)

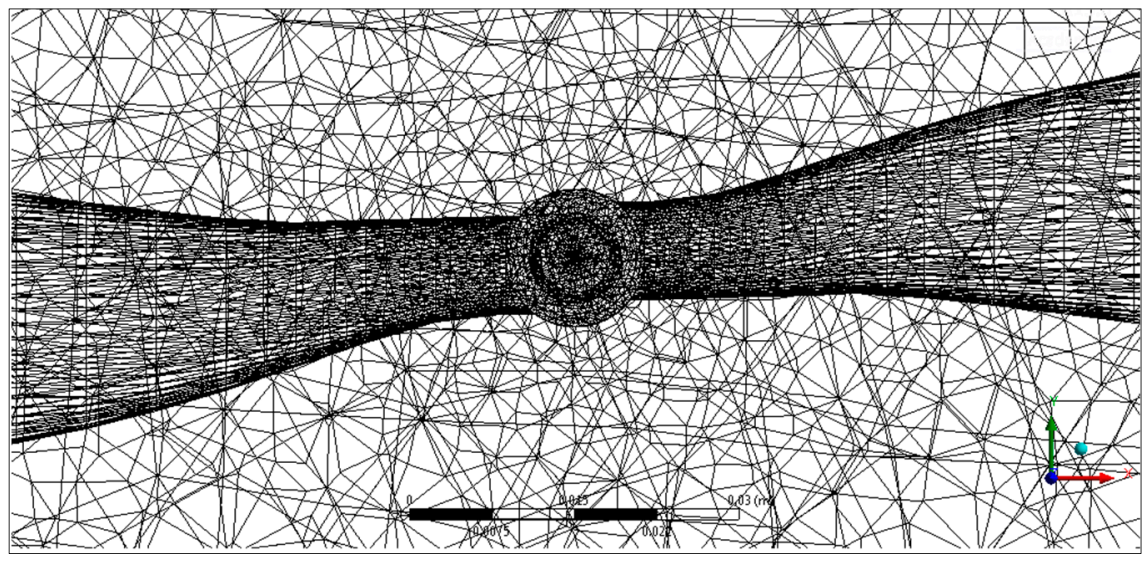

Figure 3. Surface mesh of the propeller blade. The cells sizes near the blade wall are smaller and increase towards the outer boundary. (a) Standard mesh; (b) Coarse mesh; (c) Mid mesh; (d) Mid-Fine mesh; (e) Fine mesh. 


\subsection{Boundary Conditions}

CFD simulations were conducted in the flow conditions summarized in Table 1, with a fixed rotational speed of 3008 RPM. On the inlet boundary, the free-stream velocity is specified, with a turbulence intensity of $0.1 \%$. The turbulence intensity is set based on the wind tunnel intensity measured by $[3,5,14]$. Outflow boundary conditions were set at the flow exits downstream of the flow domain. A no-slip condition is set on the walls. The domain that enclosed the propeller blade is assigned with the MRF to incorporate the rotational speed.

The approach is highly suitable for the analysis, which requires the interaction between stationary and rotating frames. The individual zones will be assigned with discrete rotational or translational speed. The interface needed between the two zones will undergo a local frame transformation to enable the flow variable from one zone to be used by the adjacent zones. The moving reference frame is assigned with a rotational speed of 3008 RPM. The wall forming the propeller blade and the hub were also assigned as rotational, with a velocity of zero with respect to the adjacent cell zone.

The pressure-velocity coupling is achieved using a Semi-Implicit Method for Pressure-Linked Equations (SIMPLE). The Second Order Upwind scheme was used for momentum and pressure. The First Order Upwind for both Turbulent Kinetic Energy and Turbulent Dissipation Rate and the Least Square Cell-based Algorithm were used for the gradients. First order algorithms provided accurate results for this study.

\section{Numerical Method Verification and Validation}

The influence of the grid and turbulence model was analysed on the prediction of the flow around the propeller to validate the method used in the study. The propeller working condition was selected based on available experimental data [1,2]. A grid resolution study was conducted to obtain the effect of the grid on the performance prediction for the propeller. Five grids, referred to as standard, coarse, mid, mid-fine, and fine, were generated based on the same geometry generation. The numbers of cells are $0.38 \times 10^{6}, 1.06 \times 10^{6}, 2 \times 10^{6}, 3 \times 10^{6}$, and $4 \times 10^{6}$, respectively.

Table 3 shows the details of the grid generated for the domain. The standard mesh was generated using default meshing in the FLUENT workbench without any modifications. The number of elements is small. The grid is further refined, which required additional manual adjustments to achieve higher grid quality. The meshing parameters, such as minimum sizing, were also further reduced, allowing increments in cells numbers. The selections of suitable meshing for the analyses were evaluated through numerical accuracy and computational times for the solutions to converge.

Apart from the meshing, three different turbulence models were tested. These include the standard $k-\varepsilon$, standard $k-\omega$, and SST $k-\omega$ turbulence model, which were tested to assess the most suitable model to predict the propeller performance. The selected turbulence model was used throughout the analysis.

Table 3. Grids for the propeller.

\begin{tabular}{cccc}
\hline Mesh & Cells & Faces & Nodes \\
\hline Standard & 380,087 & 775,533 & 70,738 \\
Coarse & $1,060,142$ & $2,161,896$ & 197,907 \\
Mid & $2,006,921$ & $4,087,759$ & 371,637 \\
Mid-Fine & $3,039,047$ & $6,196,556$ & 564,252 \\
Fine & $4,093,554$ & $8,340,019$ & 797,621 \\
\hline
\end{tabular}

\section{Results and Discussions}

The numerical analysis results were compared with available experimental data to verify the influence of the grid and the quality of the obtained data. For all the computational analyses, the force and momentum were resolved in a three-coordinate system, whose parameters are $x, y$, and $z$. The axial force and momentum around the propeller axis define the thrust and torque, respectively. Thrust 
coefficient, $K_{T}$, torque coefficient, $K_{Q}$, and power coefficient, $K_{P}$, advance ratio, $J$ and efficiency, $\eta$ are defined in Equations (1)-(7).

In these equations, $T(\mathrm{~N})$ is thrust, $Q(\mathrm{~N} \cdot \mathrm{m})$ is torque, $n(\mathrm{rps})$ is the rotational speed of the propeller, $D(\mathrm{~m})$ is the diameter of the propeller, and $\rho\left(\mathrm{kg} \cdot \mathrm{m}^{-3}\right)$ is the density of the fluid. The relative percentage error of the thrust coefficient, $K_{T}$, and torque coefficient, $K_{Q}$, can be calculated by the Equations (4) and (5), as listed below:

$$
\begin{gathered}
K_{T}=\frac{T}{\rho n^{2} D^{2}} \\
K_{Q}=\frac{Q}{\rho n^{2} D^{5}} \\
K_{P}=\frac{P}{\rho n^{3} D^{5}} \\
\Delta K_{T}(\%)=\frac{K_{T_{C F D}}-K_{T_{E X P}}}{K_{T_{E X P}}} \times 100 \\
\Delta K_{Q}(\%)=\frac{K_{Q_{C F D}}-K_{Q_{E X P}}}{K_{Q_{E X P}}} \times 100 \\
J=\frac{V}{n D} \\
\eta=\frac{K_{T} J}{K_{P}}
\end{gathered}
$$

Table 4 shows the mesh independence study summary. The error indicates the numerical and experimental discrepancy. All the meshing presented gives satisfactory results, with errors less than $5 \%$. The analysis showed that the thrust coefficient for coarse meshing resulted in the minimum error and the highest error for the efficiency. Similarly, coarse, mid, mid-fine, and fine meshing implied a primarily high error for both the thrust and power coefficient.

Table 4. Computational results at different mesh resolutions with a standard $k-\omega$ turbulence model for $J=0.628$.

\begin{tabular}{cccc}
\hline \multirow{2}{*}{ Mesh } & \multicolumn{3}{c}{ Error (\%) } \\
\cline { 2 - 4 } & $\boldsymbol{K}_{\boldsymbol{T}}$ & $\boldsymbol{K}_{\boldsymbol{Q}}$ & Efficiency, $\boldsymbol{\eta}$ \\
\hline Standard & 3.3020 & 2.7723 & 0.5010 \\
Coarse & 2.3817 & 4.1530 & 1.8928 \\
Mid & 3.3282 & 4.0127 & 0.7574 \\
Mid-Fine & 4.4237 & 4.0175 & 0.3795 \\
Fine & 4.3530 & 4.2559 & 0.3795 \\
\hline
\end{tabular}

Utilizing standard meshing is more suitable because all listed errors appeared to be optimized for thrust, power, and efficiency. Thus, the standard mesh is concluded to be sufficient for the efficient prediction of the thrust, power and efficiency for this case study; it was thus used during the entire study.

Table 5 shows the result obtained on the meshes in combination with the three-turbulence model. In general, the predictions generated from the standard $\mathrm{k}-\omega$ turbulence model provided slightly more accurate results than the other models. The standard $k-\omega$ turbulence model is more suitable for aerospace low Reynolds number applications. In addition, the model managed to predict the transition model, and increase the accuracy of the model [17]. Thus, the analyses in the study were done using this turbulence model. 
Table 5. Computational results with a different turbulence model for $J=0.628$.

\begin{tabular}{cccc}
\hline \multirow{2}{*}{ Turbulence Model } & \multicolumn{3}{c}{ Error (\%) } \\
\cline { 2 - 4 } & $\boldsymbol{K}_{\boldsymbol{T}}$ & $\boldsymbol{K}_{\boldsymbol{Q}}$ & Efficiency, $\boldsymbol{\eta}$ \\
\hline Standard k- $\varepsilon$ & 2.3817 & 4.1530 & 1.8928 \\
Standard k- $\omega$ & 2.6997 & 2.9662 & 0.3187 \\
SST k- $\omega$ & 3.4175 & 3.8805 & 0.5258 \\
\hline
\end{tabular}

Figure 4 shows the variation of the thrust coefficient, power coefficient, and efficiency with a range of advance ratios, $J$, and their percentage differences are tabulated in Table 6. Generally, the accuracy of the numerical analysis depends on the advance ratio, J. For the thrust coefficient, the results obtained from the numerical analysis indicate under-prediction for an advance ratio ranging from 0.192 to 0.659 . Meanwhile the remaining advance ratio exhibits over-prediction with the highest discrepancy of $46.27 \%$ for an advance ratio of 0.799 .

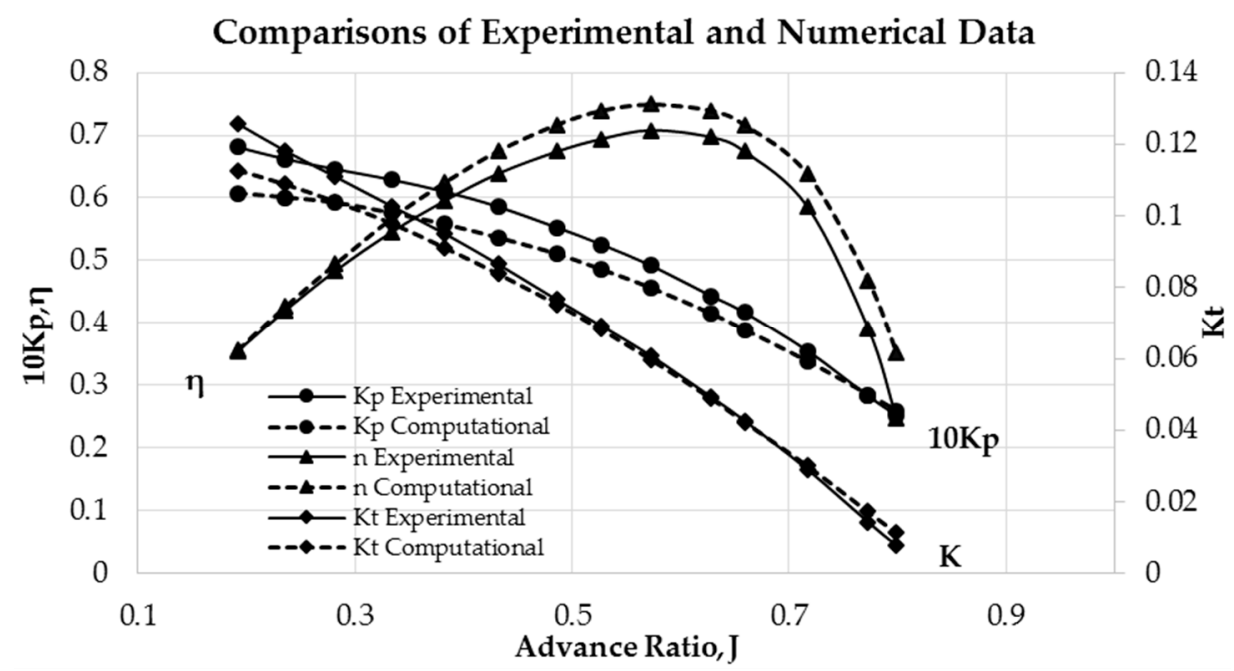

Figure 4. Comparisons of the thrust coefficient, power coefficient, and efficiency of the APC Slow Flyer Propeller.

Table 6. Difference between experimental and computational analysis for a range of advance ratios, $J$.

\begin{tabular}{ccccc}
\hline \multirow{2}{*}{ Advance Ratio, $\boldsymbol{J}$} & \multirow{2}{*}{ Velocity (m/s) } & \multicolumn{3}{c}{ Percentage Difference (\%) } \\
\cline { 3 - 5 } & & $\boldsymbol{K}_{\boldsymbol{T}}$ & $\boldsymbol{K}_{\boldsymbol{p}}$ & Efficiency, $\boldsymbol{\eta}$ \\
\hline 0.192 & 2.4384 & -10.334 & -10.749 & 0.294 \\
0.236 & 2.9972 & -7.891 & -9.204 & 1.451 \\
0.282 & 3.5814 & -6.250 & -8.245 & 2.198 \\
0.334 & 4.2418 & -4.660 & -8.399 & 3.956 \\
0.383 & 4.8641 & -4.120 & -8.512 & 4.884 \\
0.432 & 5.4864 & -3.063 & -8.413 & 5.623 \\
0.486 & 6.1722 & -1.661 & -7.657 & 6.365 \\
0.527 & 6.6929 & -1.486 & -7.608 & 6.521 \\
0.573 & 7.2771 & -1.747 & -7.291 & 5.820 \\
0.628 & 7.9756 & -0.854 & -6.492 & 6.076 \\
0.659 & 8.3693 & -0.812 & -6.776 & 6.275 \\
0.717 & 9.1059 & 3.680 & -4.843 & 8.904 \\
0.773 & 9.8171 & 20.484 & 0.520 & 19.737 \\
0.799 & 10.1473 & 46.265 & 2.803 & 42.455 \\
\hline
\end{tabular}


The power coefficient was also plotted against the advance ratio range. The result also showed a similar pattern, in which under-prediction occurs in a low advance ratio, and over-prediction occurs for a higher advance ratio. The highest discrepancy can be observed at the advance ratio of 0.192 with under-prediction of $10.75 \%$.

In addition, the propeller efficiency experienced over-prediction throughout the whole range of the advance ratios as illustrated in Figure 4. Generally, the discrepancy increases as the advance ratio increases. Above an advance ratio of 0.717 , the difference becomes substantial. At an advance ratio of 0.799 , the numerical result over-predicted the experimental value by $42.5 \%$. Analyses at a wider range of advance ratio predicting both the thrust and power coefficients were underestimated at a lower advance ratio, and the opposite behaviour was recorded at a higher value of advance ratio. This discrepancy may be attributed by the three-dimensional effect.

Figure 5 shows the pressure contour of the propeller blade operating at an advance ratio of $J=0.628$. Based on the figure, it can be seen clearly that the pressure at the back-side of the propeller is slightly higher than the pressure at the front-side of the propeller. As in the aircraft wing, the pressure difference between the top and bottom surface of the wing creates lift force, allowing the aircraft to fly. In the case of the propeller, the pressure difference between the front- and back-side of the propeller is creating force in the forward direction, known as thrust.

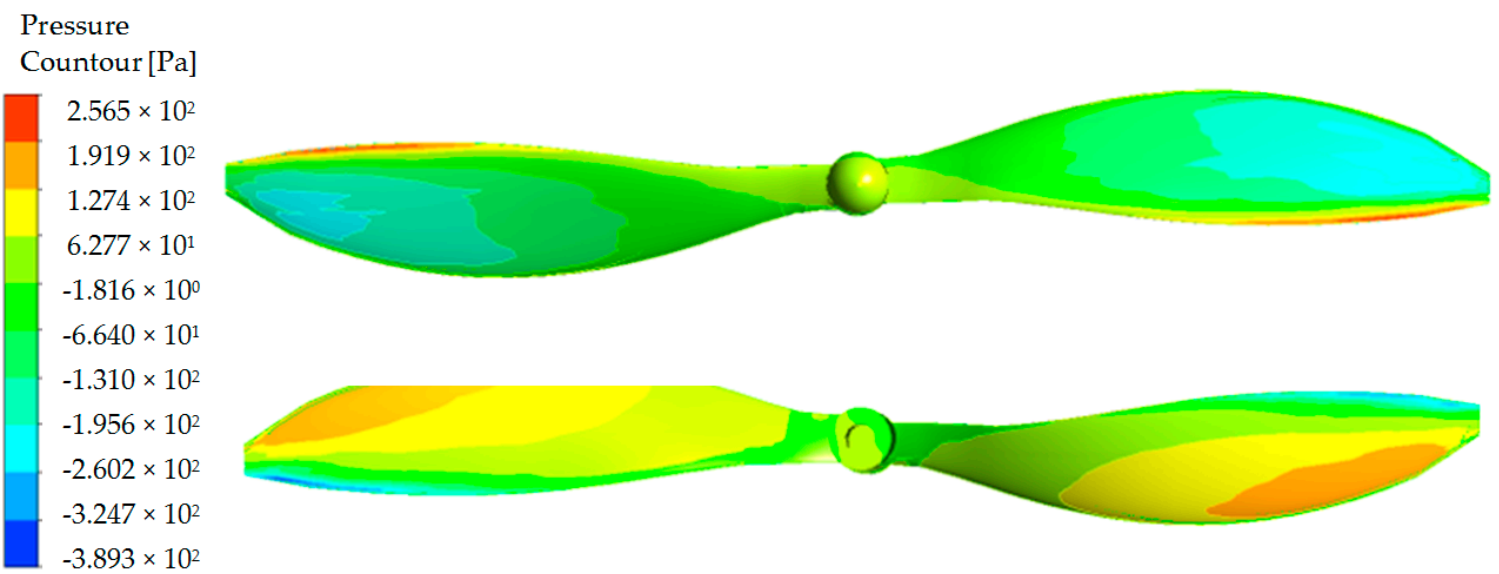

Figure 5. Propeller blade pressure contour for $J=0.628$. (Top) Front-side of the propeller; (Bottom) Back-side of the propeller.

\section{Conclusions}

CFD simulations used in this study successfully replicated the experimental results, which may significantly improve computational accuracy. The current study opens opportunities to investigate different propeller blade configurations; reliable datasets may be collected for small-scale low Reynolds number propellers. The commercial CFD code, such as FLUENT, was found to be reliable in providing good initial predictions; thus, it can replace experimental analysis, which is time-consuming and more expensive.

The method proposed in this study utilizes a standard k- $\omega$ turbulence model and a Multiple Reference Frame model to include the rotational effect of the propeller blade. The mesh independent study investigated the effects of the meshing number on the entire domain, as well as the error and computational time required for decision-making on the final meshing.

The results for the thrust coefficient showed a slight under-prediction for a low advance ratio, whereas the result for the power coefficient shows both an under-prediction for a low advance ratio and an over-prediction for a higher advance ratio. Efficiency was high throughout the advance ratio, with only a slight over-prediction on the higher advance ratio. Overall results showed a reliable capability to predict the performance of a low-speed, low Reynolds number small-scale propeller. 
Acknowledgments: This publication was supported by Universiti Sains Malaysia Grant No. 304/PAERO/ 60313056.

Author Contributions: Hairuniza Ahmed Kutty and Parvathy Rajendran conceived and designed the experiments; Hairuniza Ahmed Kutty performed the experiments; Hairuniza Ahmed Kutty and Parvathy Rajendran analyzed the data; Hairuniza Ahmed Kutty and Parvathy Rajendran wrote the paper.

Conflicts of Interest: The authors declare no conflict of interest.

\section{References}

1. Delp, F. Aircraft Propellers and Controls, 1st ed.; Jeppesen: Frankfurt, Germany, 1979.

2. Watts, H.C. The Design of Screw Propellers: With Special Reference to Their Adaptation for Aircraft, 1st ed.; Forgotten Books: London, UK, 1920.

3. Deters, R.W.; Krishnan, G.K.A.; Selig, M.S. Reynolds number effects on the performance of small-scale propellers. In Proceedings of the 32nd AIAA Applied Aerodynamics Conference, Atlanta, GA, USA, 16-20 June 2014; pp. 1-43.

4. Venkatesh, B.J. Design and Performance Evaluation of a Propeller; LAP LAMBERT Academic Publishing GmbH \& Co. KG: Saarbrücken, Germany, 2012.

5. Brandt, J.B.; Selig, M.S. Propeller Performance data at low reynolds numbers. In Proceedings of the 49 th AIAA Aerospace Sciences Meeting, Grapevine, TX, USA, 7-10 January 2013; pp. 1-18.

6. Merchant, M.P. Propeller Performance Measurement for Low Reynolds Number Unmanned Aerial Vehicle Applications; Wichita State University: Wichita, KS, USA, 2004.

7. Subhas, S. CFD analysis of a propeller flow and cavitation. Int. J. Comput. Appl. 2012, 55, 26-33.

8. Wang, X.; Walter, K.S. Computational analysis of marine-propeller performance using transition-sensitive turbulence modeling. J. Fluids Eng. 2012, 134, 071107. [CrossRef]

9. Morgut, M.; Nobile, E. Influence of grid type and turbulence model on the numerical prediction of the flow around marine propellers working in uniform inflow. Ocean Eng. 2012, 42, 26-34. [CrossRef]

10. Ernesto Benini, Ã. Significance of blade element theory in performance prediction of marine propellers. Ocean Eng. 2004, 31, 957-974. [CrossRef]

11. Morgado, J.; Silvestre, M.Â.R.; Páscoa, J.C. Validation of new formulations for propeller Analysis. J. Propuls. Power 2015, 31, 467-477. [CrossRef]

12. Morgado, J.; Silvestre, M.A.R.; Páscoa, J.C. A comparison of post-stall models extended for propeller performance prediction. Aircr. Eng. Aerosp. Technol. 2016, 88, 540-549. [CrossRef]

13. Morgado, J.; Abdollahzadeh, M.; Silvestre, M.A.R.; Páscoa, J.C. High altitude propeller design and analysis. Aerosp. Sci. Technol. 2015, 45, 398-407. [CrossRef]

14. Brandt, J.B.; Deters, R.W.; Ananda, G.K.; Selig, M.S. UIUC propeller data site. Available online: http://m-selig.ae.illinois.edu/props/propDB.html (accessed on 1 November 2016).

15. APC Slow Flyer. Available online: https://www.apcprop.com/Articles.asp?ID=262\#airfoil (accessed on 10 September 2016).

16. ANSYS, Inc. ANSYS Fluent User's Guide. Available online: http://159.226.251.229/videoplayer/ANSYS\% 20Fluent\%20Users\%20Guide.pdf?ichuri=4430682d62b326e212655a3feab3426a\&ichstart=0\&ichend=0\& ichkey=1745028923750463592455\&ichtype=1\&ichdiskid=1\&ichunit=1 (accessed on 15 January 2017).

17. ANSYS, Inc. Modeling Turbulent Flows, Introductory Fluent Training. Available online: http://www. southampton.ac.uk/ nwb/lectures/GoodPracticeCFD/Articles/Turbulence_Notes_Fluent-v6.3.06.pdf (accessed on 15 January 2017).

(C) 2017 by the authors. Licensee MDPI, Basel, Switzerland. This article is an open access article distributed under the terms and conditions of the Creative Commons Attribution (CC BY) license (http://creativecommons.org/licenses/by/4.0/). 